\title{
Acute Paraphenylenediamine (PPD) Toxic Effects upon the Kidney after Single Oral Dose: An Experimental Study
}

\author{
Abdel-wahab A. Dawood', Maha A. Hilal, Soheir A. Mohammed, Reda M. \\ Elsayed $^{2}$, Khaled M. Mohamed ${ }^{3}$ and Hoda M. Elsayed ${ }^{4}$
}

\footnotetext{
${ }^{1}$ Forensic Medicine and Clinical Toxicology Department, Faculty of Medicine, Assiut University

${ }^{2}$ Forensic Medicine and Clinical Toxicology Department, Faculty of Medicine, Sohag University, Egypt.

${ }^{3}$ Assiut Chemical Laboratory, Medico-Legal Department, Ministry of Justice, Egypt.

${ }^{4}$ Histology Department, Faculty of Medicine, Sohag University, Egypt.
}

\begin{abstract}
Paraphenylenediamine (PPD) is a synthetic compound used widely as a hair dye. Ingestion of PPD results in major systemic problems which depend mainly on the dose taken.

The current study was designed to investigate PPD toxic effects upon the kidney after single oral dose of PPD in three groups of adult male albino rats. Groups II, III, and IV which received (8, 16, 80 $\mathrm{mg} / \mathrm{kg}$ toxic, sublethal and lethal dose of PPD respectively), 10 per each group. Another 10 animals were served as a control group (group I) received only distilled water. Blood was collected for evaluation of kidney functions and measurement of PPD and its metabolites levels by HPLC. The kidneys were preserved for histopathological examinations and measurement of the level of PPD and its metabolites by HPLC. The results proved that acute ingestion of PPD can induce disturbed kidney functions. PPD was detected in plasma and the kidney in group IV and in the kidney only in group II and group III, while the metabolites (MAPPD and DAPPD) were detected in all treated groups. The histopathological findings showed that PPD cause mild, moderate and severe tubular damage. In a conclusion, this study established the renal toxic effects of acute ingestion of paraphenylene-diamine.
\end{abstract}

Keywords Paraphenylenediamine (PPD), renal toxicity, oral exposure HPLC

\section{Introduction}

$\mathrm{P}$ araphenylene-diamine (PPD) is a synthetic compound that is widely used as a hair dye, in fur and dark cosmetics and temporary tattoo. It is mainly used to intensify the black color produced by henna (Lawsonia inermis) and to reduce the time required for dyeing and decorating hands and feet with henna. (Saad et al., 2000).

PPD is a colorless, slightly pink, grey or yellow crystalline solid (lump or powder). On oxidation, usually through exposure to air, it turns red, brown, and then finally black. (Mathur et al., 1990).

Hair dyes containing PPD were used in some communities for criminal and abortive purposes and more frequently for attempted suicide or sometimes accidentally ingested. PPD is the most widely used intermediate in hair dye formulations. (Schnuch et al., 1997).

PPD is rapidly absorbed into blood through mucous membranes of the digestive tract after its oral intake. It is metabolized into quinonediimine, which acts as a cytotoxin. It is acetylated into N-acetyl-p- phenylenediamine (MAPPD) and N, N-diacetylpphenylenediamine (DAPPD) as the major metabolites for detoxification to be excreted into urine. (Mohamed et al., 2014).

PPD has been detected in blood, urine and gastric content by gas chromatography-mass spectrometry (GC-MS) after liquid-liquid extraction. Methods involving liquid chromatography (LC) with electrochemical detector, ultraviolet, diode array, or MALDI-MS/MS for quantification of PPD and its metabolites have been reported. (Mohamed et al., 2014).

\section{Materials and Methods}

\section{Animals}

The present study was conducted on forty (40) white albino male rats were supplied by the Animal Facility Centre of Faculty of Medicine, Assiut University. The animals were housed in animal house, Faculty of Medicine, Sohag University, in metal cages under 
ambient temperature, $21 \pm 3{ }^{\circ} \mathrm{C}$, and they were acclimatized to the laboratory condition for 24 hours before starting the treatment protocol. The ethics and husbandry conditions of animal research were considered according to the guide of care and use of laboratory animals approved by the Ethical Committee of Faculty of Medicine Sohag University. Animals were fed with standard pellet feed and water.

\section{Chemicals and Reagents}

- Kits for measurement of urea, creatinine and creatine phosphokinase (CPK) were purchased from Beckman Coulter Inc. Company.

- The test chemical (p-phenylenediamine), aniline (internal standard, IS) (>98\%) and PPD $2^{\text {nd }}$ metabolite Diacetyl pphenylenediamine (DAPPD) in the form of $100 \mathrm{gm}$ powder were purchased from SigmaAldrish CO.

- PPD metabolite Monoacetyl pphenylenediamine (MAPPD) was prepared in Sohag Clinical Toxicology Lab by Dr. Khaled Masoud according to: (Kawakubo. Et al., 2000) method.

- Methanol, Dichloromethane and Acetonitrile HPLC grade from Sigma- Aldrish CO.

- Deionized water from Human Power 1water Deionizer.

- $\mathrm{pH}$ Buffer: (o-phosphoric acid, potassium dihydrogen phosphate) from Sigma- Aldrish CO.

- Ammonia 33\% commercial from El-Nasr Company.

\section{Instruments}

1. Beckman Coulter AU480 Clinical Chemistry System: Fully automated, Analytical Principles: Spectrophotometry and potentiometry.

2. High Performance Liquid Chromatography (HPLC) instrument (Agilent; USA): consisted of an Agilent technologies 1200 series quaternary pump combined with photo diode array detector (USA), vacuum degasser (USA) and an Agilent autosampler injector. Chromatographic separation was performed on a Zorbax eclips- C18 (150 mm ×4.6 mm, 5 $\mu \mathrm{m})$ column (USA). HPLC presents in Sohag Clinical Toxicology Lab.

3. Vortex, Gemy industrial crop - model: VM300, Centrifuge, Hettich Zentifugen model: EBA20, Rotator, Bibby Scientific model: SB3, Water deionizer: Human corporation - model: Human power 1, $\mathrm{pH}$ meter: Hanna Instrument Romania - model: PH 211: for buffer formation, Magnetic stirrer: IKA-WERKE company model: IKA RH basic 2, Micropipettes: HTL - model: OP1000, Analytical balance: A\&D Company, Limited - model: GR 200

4. Olympus CX 41 RF Light microscopy.

\section{Animals groups and methods}

Animals were randomly divided into 4 groups (10 animals for each group):

- Group I: Rats were treated with $2 \mathrm{ml}$ of distilled water alone once orally through gastric tube (control group).

- Group II: Rats were treated with (PPD) dissolved in $2 \mathrm{ml}$ of distilled water once orally through gastric tube in a dose $8 \mathrm{mg} / \mathrm{kg}$ body weight (B.wt.) (toxic dose 1/10LD50) (Kazuhiro and Takaaki, 2005)

- Group III: Rats were treated with (PPD) dissolved in $2 \mathrm{ml}$ of distilled water once orally through gastric tube in a dose $16 \mathrm{mg} / \mathrm{kg}$ B.wt. (sublethal dose 1/5LD50)

- Group IV: Rats were treated with (PPD) dissolved in $2 \mathrm{ml}$ of distilled water once orally through gastric tube in a dose $80 \mathrm{mg} / \mathrm{kg}$ B.wt. (lethal dose LD50). (Kazuhiro and Takaaki, 2005)

The animals of groups III and IV were slaughtered by cut throat after giving them light inhalational anesthesia (ether) immediately before death (4-8 hours) after dose administration manifested by (cyanosis, bull neck, frothy secretions, protruded tongue and convulsions) while the animals of groups I, II were slaughtered 24 hours after dose administration. (Saad et al., 2000)

\section{Collection of samples}

- Six ml of blood were drawn from each rat from cervical blood vessels during slaughtering into clean dry tubes. Each sample divided into two equal parts (three $\mathrm{ml}$ for each). The first one for serum biomarkers (urea \& creatinine) in which the serum was obtained immediately after sampling by centrifugation (4000 rpm for 5 minutes) and transferred into sterile screw capped polypropylene tubes and stored at $-20{ }^{\circ} \mathrm{C}$ until analysis. The second part were put in heparinized tubes from which plasma was obtained by centrifugation (4000 rpm for 5 minutes) and placed into sterile screw capped polypropylene tubes and stored at $-20{ }^{\circ} \mathrm{C}$ until HPLC analysis.

- Autopsy was done for all animals where both kidneys were removed and preserved for histopathological examination and PPD detection in the kidney tissue.

\section{[A] Analytical Toxicology}

\section{Extraction Procedure}

\section{For plasma samples}

Liquid/liquid extraction was performed by adding $100 \mu \mathrm{L}$ of aniline HCL $(100 \mu \mathrm{g} / \mathrm{ml}), 100 \mu \mathrm{L}$ of conc. ammonium hydroxide (33\%) and six $\mathrm{ml}$ of dichloromethane to one $\mathrm{ml}$ of plasma in ten $\mathrm{ml}$ polypropylene tubes. The tubes were then mixed by rotator at the rate of $40 \mathrm{rpm}$ for 20 minutes and centrifuged at $3500 \mathrm{rpm}$ for five minutes. The lower organic layer was transferred to ten $\mathrm{ml}$ glass tubes and evaporated to dryness. The dried extracts were 
reconstituted in $200 \mu \mathrm{L}$ mobile phase (ACN: buffer), vortex mixed for 30 seconds and $100 \mu \mathrm{L}$ was injected into the HPLC system.

\section{For the kidney samples}

To each one gm of tissue, three $\mathrm{ml}$ of phosphate buffer $\mathrm{pH} 3$ added to the sample which homogenized by tissue homogenizer (at $50 \mathrm{rpm}$ for five minutes) and then centrifuged at $3500 \mathrm{rpm}$ for ten minutes. The supernatant separated to be extracted and analyzed by HPLC.

\section{HPLC Analysis}

The mobile phase consisted of acetonitrile: buffer $(0.01 \mathrm{M})$ potassium dihydrogenphosphate (10: 90, v/v), adjusted to $\mathrm{pH} 5.2$ with $0.1 \mathrm{M}$ sodium hydroxide. The separation was performed at $25^{\circ} \mathrm{C}$ with flow rate of 0.5 $\mathrm{ml} / \mathrm{min}$ in the first five minutes then $1.5 \mathrm{ml} /$ minutes for the last ten minutes. The detector was set to scan from 200 to $800 \mathrm{~nm}$ and had a discrete channel set at $240 \mathrm{~nm}$ and 260nm. PPD, MAPPD and DAPPD concentration in the samples was determined from the standard curve, using peak area ratio for quantification.

\section{[B] Bio Chemical Tests}

The serum biomarkers of renal function (urea and creatinine) and serum CPK level were investigated where the biochemical assay was done according to the manufacturer's instructions within two days of serum separation and absorbance was recorded with Clinical Chemistry System (AU 480).

\section{[C] Histopathological Examination}

The kidney was fixed in formalin $10 \%$ and paraffin embedding five $\mu \mathrm{m}$ sections were cut and stained with Hematoxylin and eosin. Sections were examined by light microscope for the evaluation of any pathological changes then photographed.

\section{[D] Statistical Analysis}

All statistical procedures were computed using Statistical Program for Social Science (SPSS), version 16.0 computer software. SPSS inc. Chicago, USA.

All data were presented as mean \pm SD and compared by Student's t-test and one way ANOVA test. p value $<0.05$ was considered as significant.

\section{Results}

\section{1- HPLC results}

Graph (1): Represents the mean values of PPD, MAPPD and DAPPD in the plasma $(0,1561.3$ and $3727.4 \mathrm{ng} / \mathrm{ml}$ respectively) and the kidney (1312.2, 930.7 and $1358.4 \mathrm{ng} / \mathrm{gm}$ respectively) of group II. PPD could not be detected in plasma but detected in the kidney while its metabolites (MAPPD and DAPPD) can be detected in both the plasma and the kidney.

Graph (2): Shows the mean values of PPD, MAPPD and DAPPD in the plasma $(0,5486.4$ and $4418.4 \mathrm{ng} / \mathrm{ml}$ respectively) and the kidney (1359.8, 1183.2 and $1430.33 \mathrm{ng} / \mathrm{gm}$ respectively) of group III. PPD could not be detected in the plasma but still detectable in the kidney while its metabolites can be detected in both plasma and the kidney.

Graph (3): Shows the mean values of PPD, MAPPD and DAPPD in the plasma 4488.3, 6332.9 and $7335.9 \mathrm{ng} / \mathrm{ml}$ respectively) and the kidney (11029.9, 1760.9 and $1959.09 \mathrm{ng} / \mathrm{gm}$ respectively) of group IV. Both PPD and its metabolites can be detected in the plasma and the kidney with high level.

\section{2- Biochemical results}

There was a significant statistical increase in the mean values of serum urea in all PPD treated rat groups II, III, IV (48.47, 40.70 and $35.65 \mathrm{mg} / \mathrm{dl}$ respectively) as compared with control group $(32.50 \mathrm{mg} / \mathrm{dl})(\mathrm{p}<0.001$, 0.001 and 0.01 respectively) Table (1).

On the other hand there was significant statistical increase in the mean value of serum creatinine only in group II $(0.79 \mathrm{mg} / \mathrm{dl})$ as compared with control group $(0.58 \mathrm{mg} / \mathrm{dl})$ while there was no significant statistical difference in the mean value of serum creatinine in group III and IV (0.66 and 0.64 $\mathrm{mg} / \mathrm{dl}$ respectively) PPD treated rats as compared with control group Table (1).

As shown in Table (2) there was significant statistical difference in the mean values of serum urea between group II and group III, between group II and group IV and finally between group III and group IV ( $\mathrm{p}$ $<0.001,0.000$ and 0.01 respectively) and among all PPD treated groups $(\mathrm{p}<0.001)$.

In spite there was significant statistical difference in the mean values of serum creatinine between group II and group III and between group II group IV ( $\mathrm{p}<0.04$ and 0.009 respectively) and among all PPD treated groups ( $\mathrm{p}<0.009)$. However, there was no significant statistical difference in the mean values of serum creatinine between group III and group IV ( $p$ $<0.7)$

There was a significant statistical increase in the mean values of serum CPK in all PPD treated groups II, III, IV (2528.7, 4059.5 and 5837.4 IU/L respectively) as compared with control group I (458.3 IU/L) ( $\mathrm{p}<0.001,0.001$ and 0.001 respectively) Table (3).

As shown in Table (4) there was significant statistical difference in the mean values of serum CPK between group II and group III, between group II and group IV and finally between group III and group IV (p $<0.001,0.001$ and 0.001 respectively) and among all PPD treated groups $(\mathrm{p}<0.001)$.

\section{3- Histopathological results}

\section{Group I (control group)}

Examination of a section from the kidney of the control group revealed normal kidney parenchyma. The parenchyma formed of renal corpuscles, proximal convoluted tubules (P.C.T), distal convoluted tubule (D.C.T), loop of Henel and collecting tubules. (Fig.1)

Group II

Partial widening of urinary space and congestion were found in some glomerular capillaries. PCT showed partial loss of brush border, widening of their lumen and karyolysis of some nuclei of their cells. Other tubules appeared normal. Distal convoluted tubular 
cells appeared with pyknotic nuclei and vaculated cytoplasm, while other cells appeared with vesicular nucluei and acidophilic cytoplasm. The peritubular capillaries showed congestion in addition to inflammatory cells in the interstitium. (Fig 2)

\section{Group III}

There is widening of the urinary space with lobulation of many glomural capillaries. PCT showed loss of brush border and widening of the lumen. Some tubules contain sheded cells in their lumen. Some PCT cells contain pyknotic nuclei and vaculated cytoplasm. Some Distal convoluted tubular cells appeared with pyknotic nuclei and vaculated cytoplasm with acidophilic material in their cytoplasm. (Fig. 3).

\section{Group IV}

The glomerular capillaries showed congestion, lobulation and partial degeneration in addition to widening of urinary spaces. The P.C.T showed widening of their lumen with loss of the brush border. Their cells showed pyknosis of the nuclei and vacuolation of their cytoplasm. The D.C.T showed pyknosis of the nuclei and vacuolation of the cytoplasm of their cells. The peritubular capillaries showed congestion (Fig. 4).

Table (1): The mean values of serum urea and creatinine in different rat groups

\begin{tabular}{|l|c|c|c|c|}
\hline \multirow{2}{*}{ Groups } & \multicolumn{2}{|c|}{ Serum urea (mg/dl) } & \multicolumn{2}{c|}{ Serum creatinine $(\mathbf{m g} / \mathbf{d l})$} \\
\cline { 2 - 5 } & Mean \pm SD & P-value & Mean \pm SD & P-value \\
\hline Group I & $32.50 \pm 1.08$ & & $0.58 \pm 0.16$ & \\
\hline Group II & $48.47 \pm 3.71$ & $0.000^{*}$ & $0.79 \pm 0.14$ & $0.006^{*}$ \\
\hline Group III & $40.70 \pm 4.88$ & $0.000^{*}$ & $0.66 \pm 0.13$ & 0.26 \\
\hline Group IV & $35.65 \pm 2.94$ & $0.005^{*}$ & $0.64 \pm 0.08$ & 0.33 \\
\hline
\end{tabular}

* Significant $P$ - value at $<0.05$

Table (2): showing the statistical difference in serum urea and creatinine between PPD treated rat groups

\begin{tabular}{|l|c|c|c|c|}
\hline \multirow{2}{*}{ Groups } & \multicolumn{2}{|c|}{ Serum urea (mg/d) } & \multicolumn{2}{c|}{ Serum creatinine (mg/dl) } \\
\cline { 2 - 2 } & P for t- test & P for ANOVA test & P for t- test & P for ANOVA test \\
\hline II Versus III & $0.001^{*}$ & & $0.04^{*}$ & \multirow{2}{*}{$0.009^{*}$} \\
\cline { 1 - 2 } II Versus IV & $0.000^{*}$ & \multirow{2}{*}{$0.000^{*}$} & $0.009^{*}$ & \multirow{2}{*}{} \\
\cline { 1 - 2 } III Versus IV & $0.01^{*}$ & & 0.7 & \\
& & &
\end{tabular}

* Significant $P$ - value at $<0.05$

Table (3): The mean values of serum CPK in different rat groups:

\begin{tabular}{|c|c|c|}
\hline \multirow[t]{2}{*}{ Groups } & \multicolumn{2}{|c|}{ Serum CPK (IU/L) } \\
\hline & Mean \pm SD & P-value \\
\hline Group IA & $458.3 \pm 33.8$ & \\
\hline Group IIA & $2528.7 \pm 189.2$ & $0.000^{*}$ \\
\hline Group IIIA & $4059.5 \pm 317.5$ & $0.000^{*}$ \\
\hline Group IVA & $5837.4 \pm 646.3$ & $0.000^{*}$ \\
\hline
\end{tabular}

Table (4): showing the statistical difference in serum CPK between PPD treated groups.

\begin{tabular}{|l|l|c|}
\hline \multirow{2}{*}{ Groups } & \multicolumn{2}{|c|}{ Serum CPK (IU/L) } \\
\cline { 2 - 2 } & P for t- test & P for ANOVA test \\
\hline IIA Versus IIIA & $0.000^{*}$ & \multirow{2}{*}{$0.000^{*}$} \\
\hline IIA Versus IVA & $0.000^{*}$ & \\
\hline IIIA Versus IVA & $0.000^{*}$ & \\
\hline
\end{tabular}

* Significant $P$ - value at $<0.05$ 


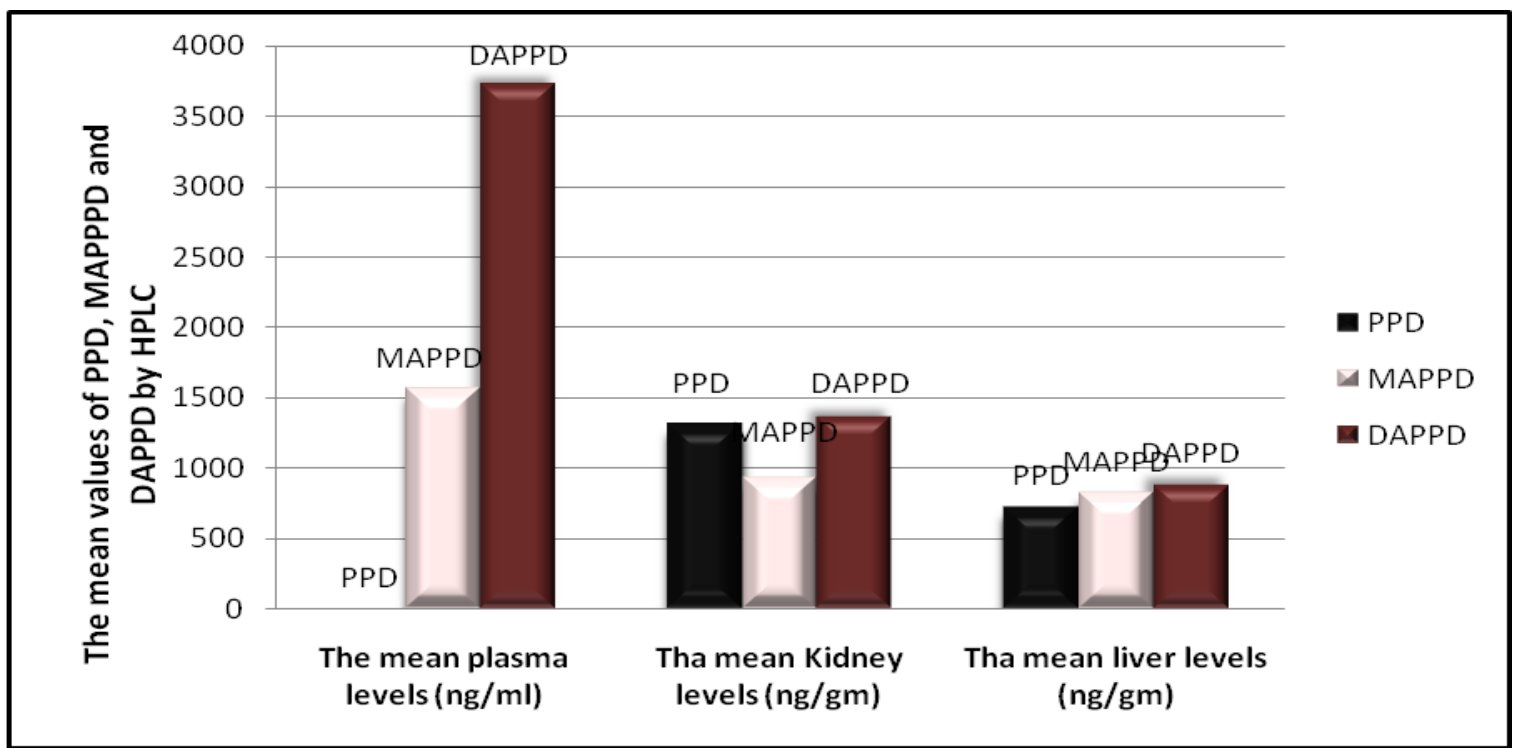

Graph (1): The mean values of PPD, MAPPD and DAPPD (ng/ml) in plasma and kidney of group II (1/10 LD50).

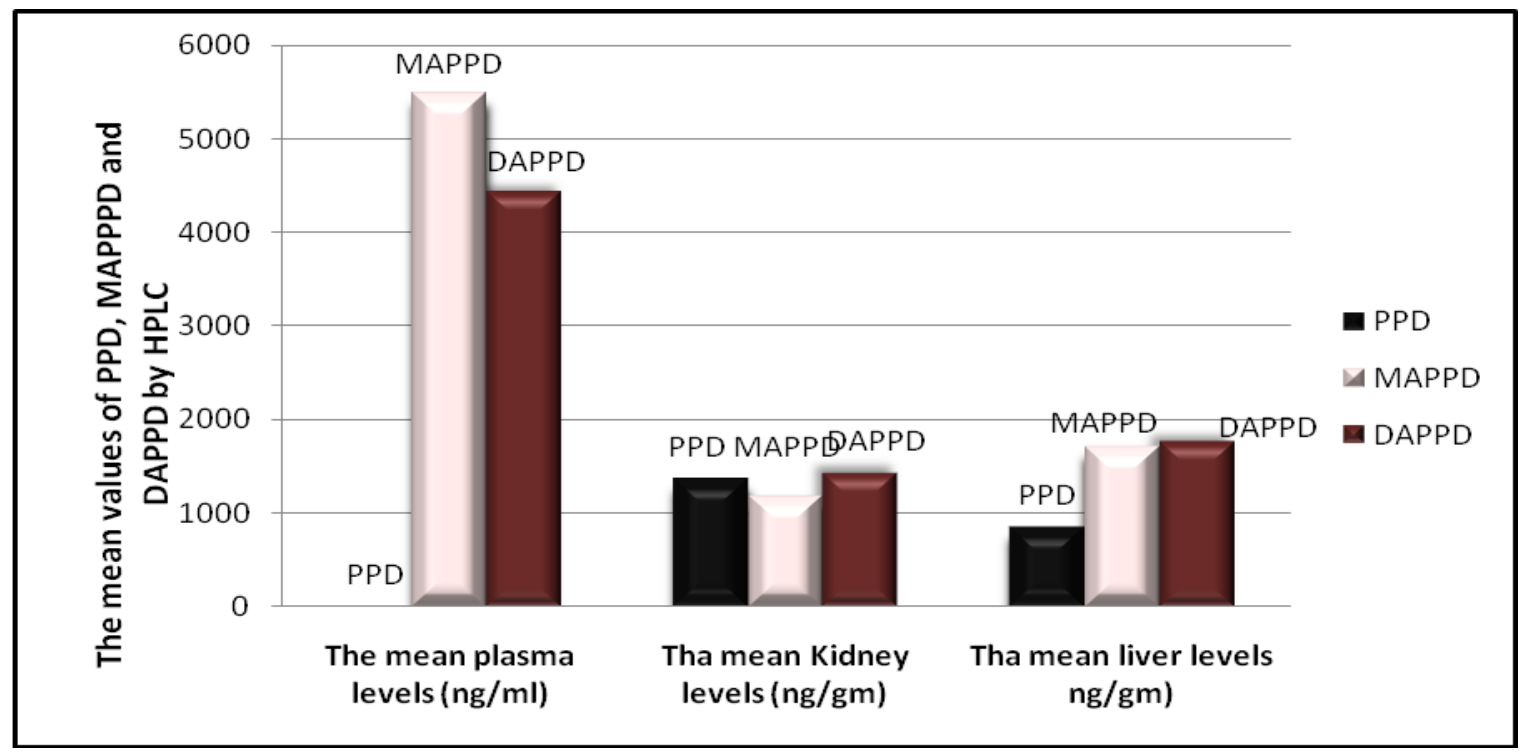

Graph (2): The mean values of PPD, MAPPD and DAPPD in plasma and kidney of group III (1/5LD50)

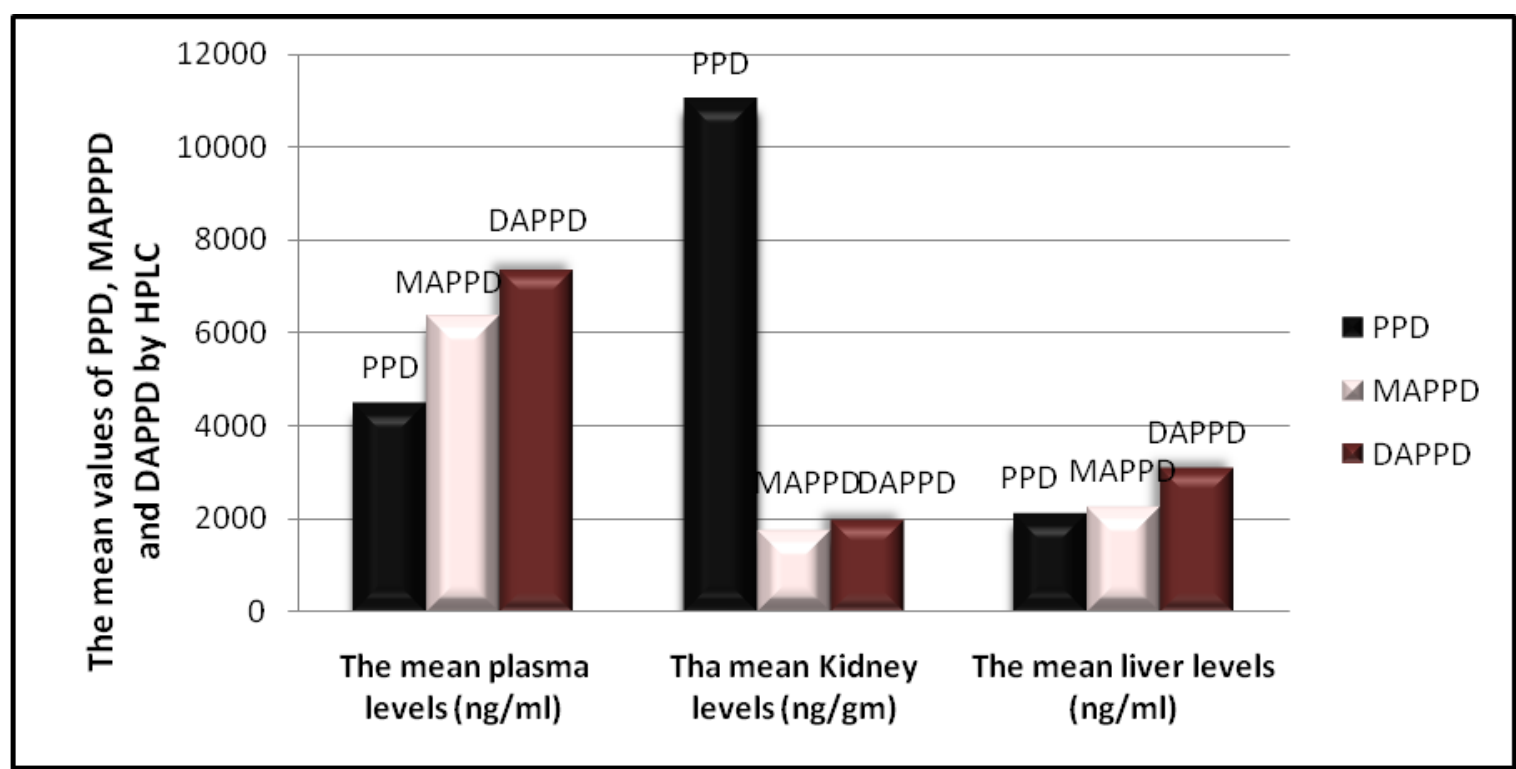

Graph (3): The mean values of PPD, MAPPD and DAPPD in plasma and kidney of group IV (LD50). 


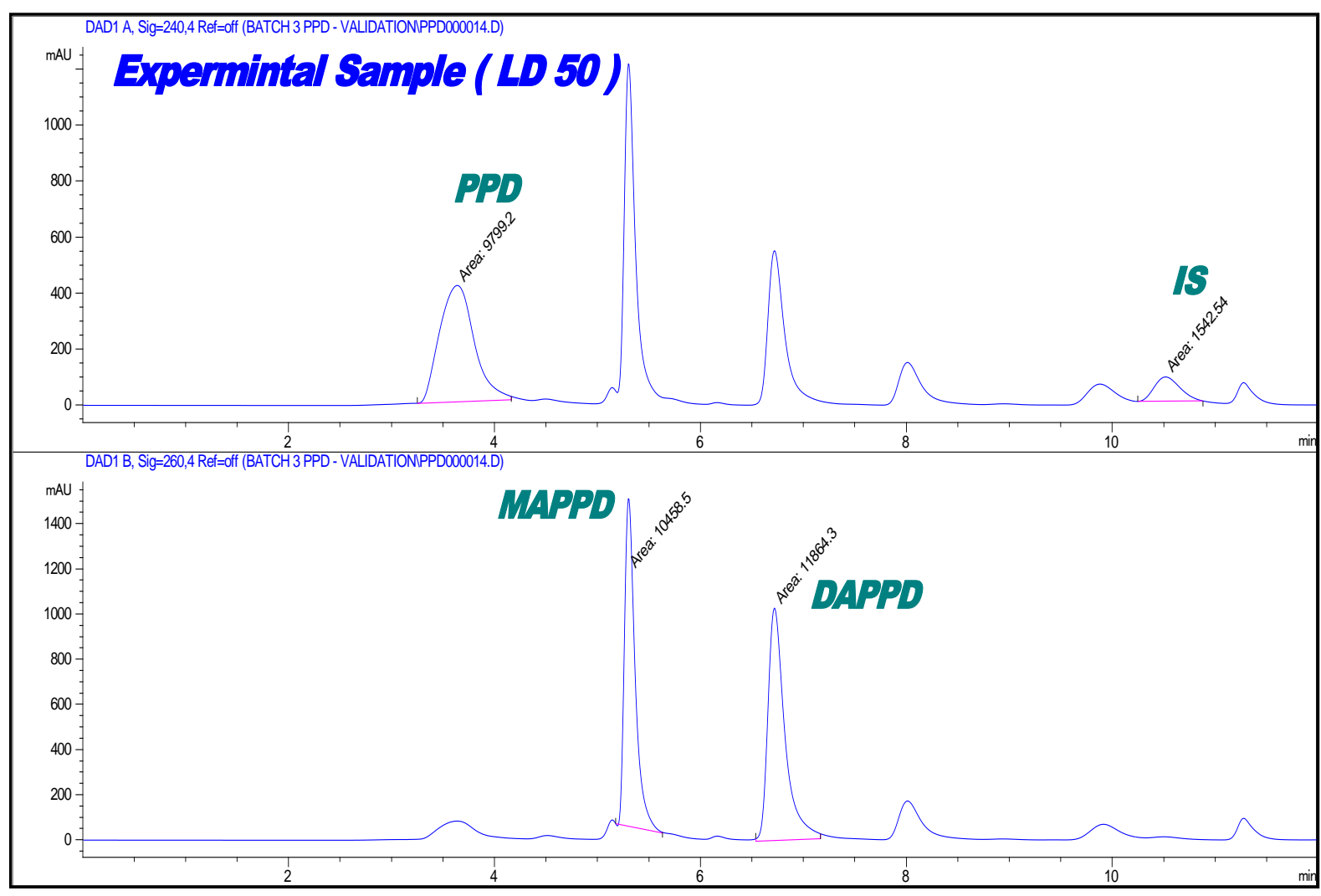

Graph (4): Showing HPLC chromatogram for detection of PPD and its metabolites in group IV

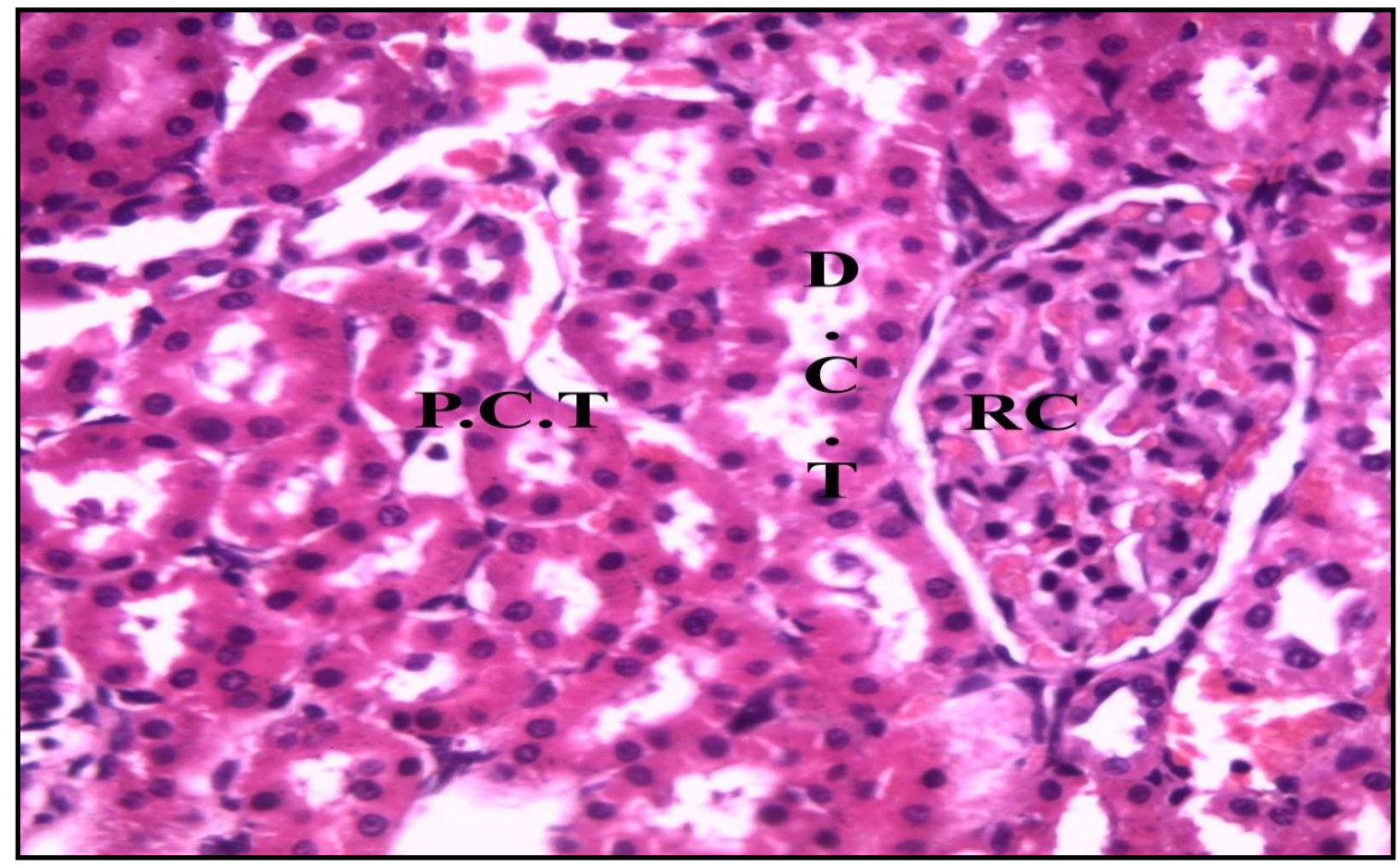

Fig. (1): A photomicrograph of a section in the kidney of control group showing normal renal corpuscle (R.C.), proximal convoluted tubules (P.C.T.) and distal convoluted tubules (D.C.T.). H\&E staining $x 400$ 


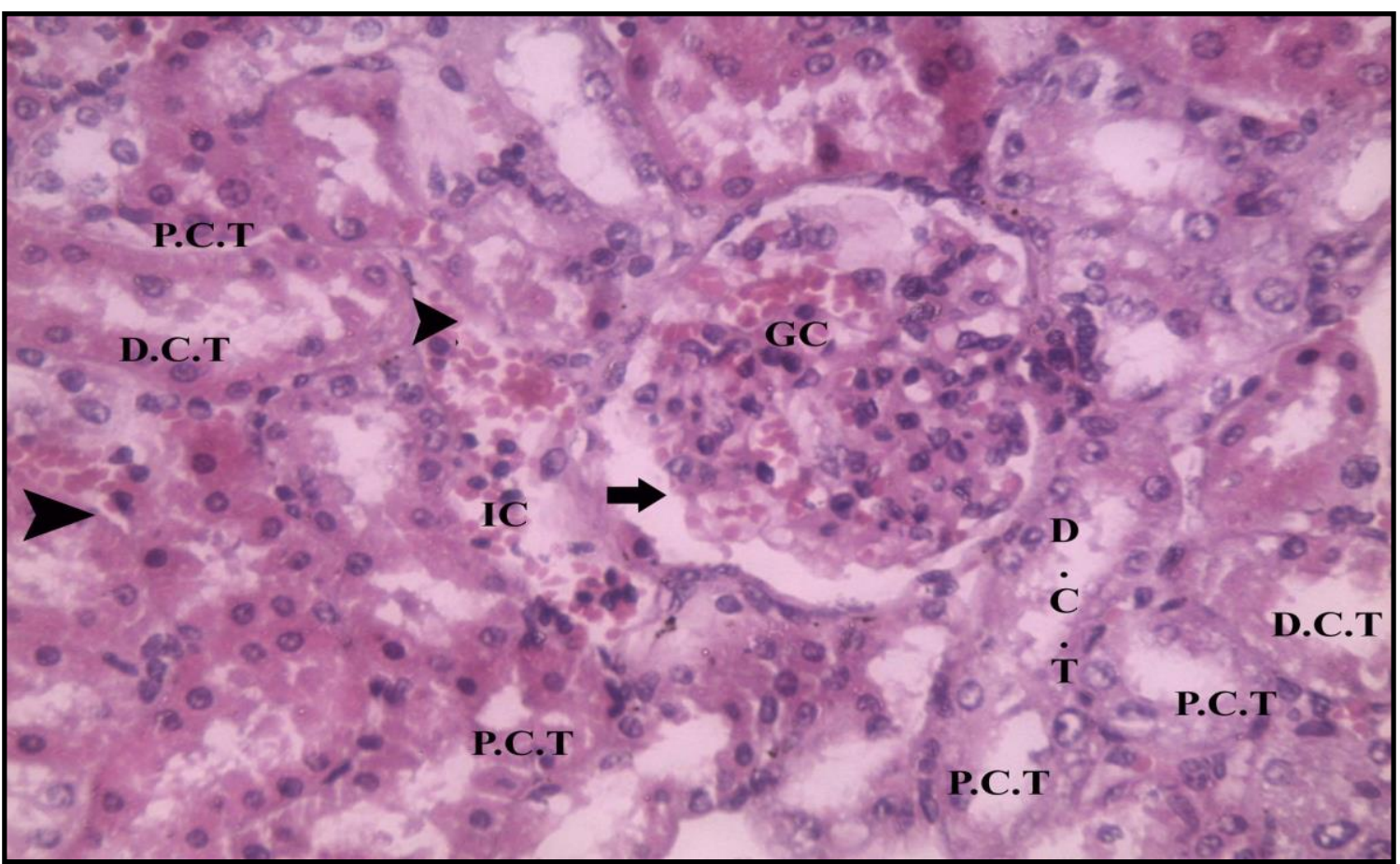

Fig. (2): A photomicrograph of a section in the kidney of group II showing widening of the urinary space (thick arrow), partial loss of brush border, congestion of some glomerular capillaries (G.C.), P.C.T. cells with pyknotic nuclei (P.C.T.) and D.C.T. cells with pyknotic nuclei and vacuolated cytoplasm (D.C.T.). Other tubules appeared normal. H\&E staining x400.

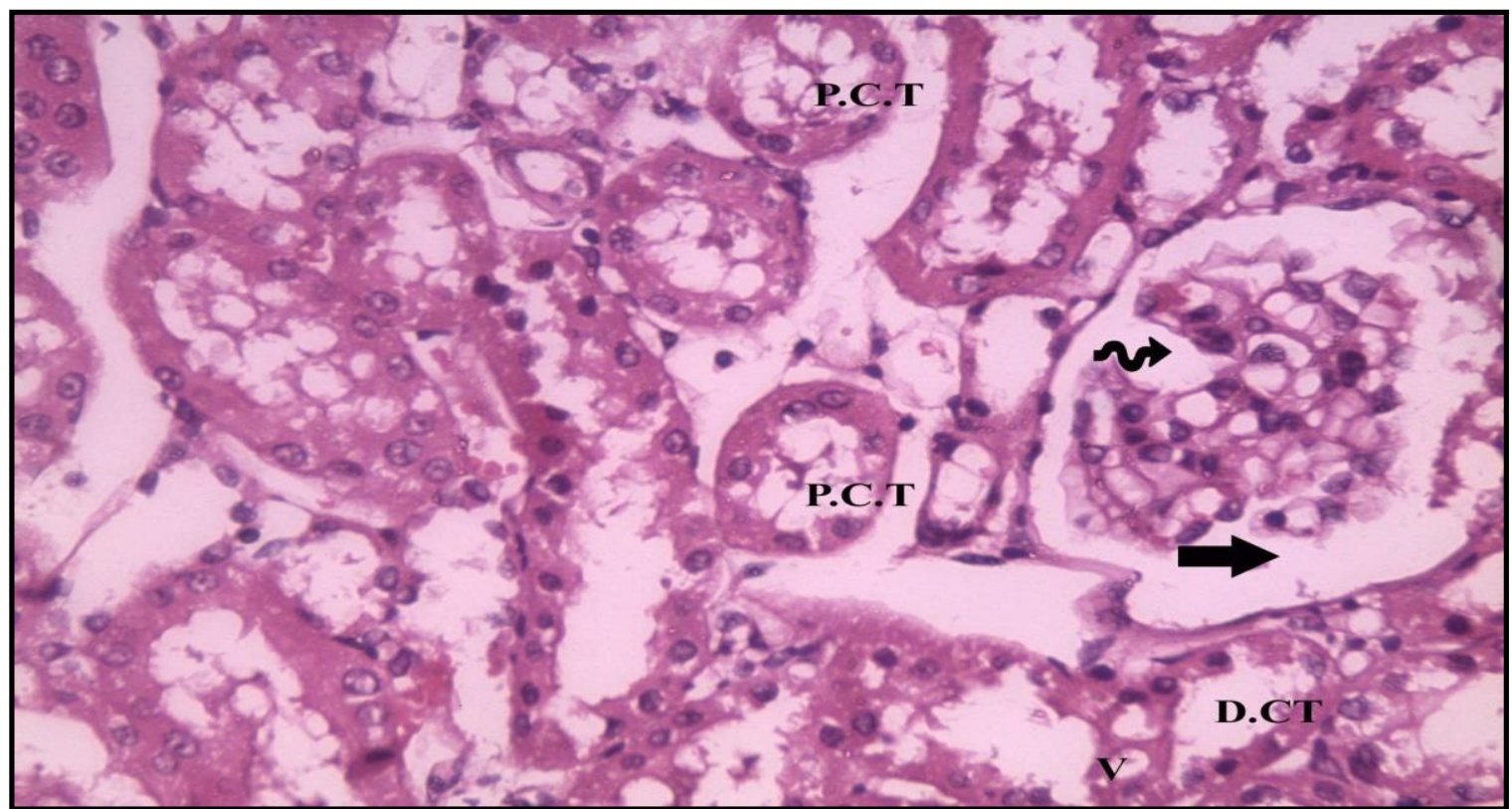

Fig (3): A photomicrograph of a section in the kidney of group III showing widening of the urinary space (thick arrow), lobulation of the glomurli (irregular arrow), P.C.T. cells with pyknotic nuclei (P.C.T.) and D.C.T. cells with pyknotic nuclei and vacuolated cytoplasm (D.C.T.). and vaculated cytoplasm (V). H\&E staining $x 400$. 


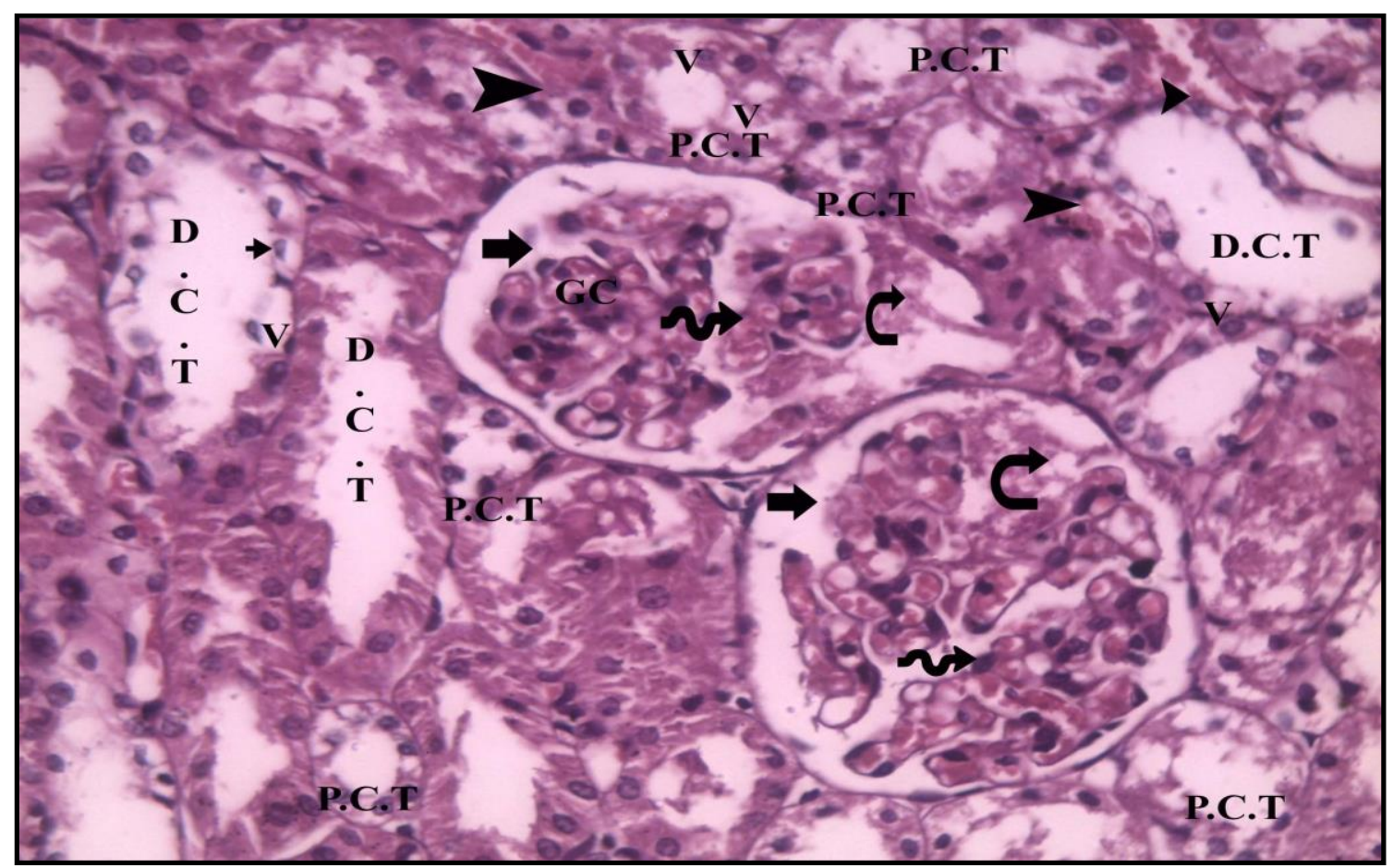

Fig (4): A photomicrograph of a section in the kidney of group IV showing marked dilatation of urinary space (thick arrow), marked congestion of glomerular capillaries (G.C.) and lobulation (irregular arrow), degeneration of others (curved arrow). Most of PCT showed degeneration of their cells (P.C.T.). D.C.T. showed pyknosis (thin arrow) and valuated cytoplasm (V). peritubular capilleries showed marked congestion (arrow head). H\&E staining x400.

\section{Discussion}

Paraphenylenediamine (PPD) also called 1, 4 diaminobenzene or 1,4 - phenylenediamine is an aromatic amine which has been used for dyeing furs, photochemical measurements and azo-dye manufacturing, as well as for oxidizing hair dyes (Bourquia et al., 1988).

As an arylamine, PPD may lose its reactivity through $\mathrm{N}$-acetylation. Therefore, $\mathrm{N}$-acetylation of PPD may be an important step for detoxification or activation of this agent (Meyer and Zanger, 1997).

Hair dye poisoning becomes one of the important etiological factors for suicide. (Krishnaswam and Sooraj, 2009)

Ingestion of PPD results in acute poisoning with major systemic problem. It results in multisystem involvement of CNS, CVS, renal \& musculoskeletal. (Mohamed et al., 2010)

The kidneys are particularly vulnerable to effects of noxious agents because of their high perfusion rate. Renal lesions associated with PPD intoxication received much attention because most of the clinical investigators reported renal failure and evidence of severe nephrotoxicity has been reported in humans. [(Averbukh et al., 1989); (Hashim et al., 1992); (Charra et al., 2000); (Othman, 2001)]

The aim of the present study was to evaluate the dose dependent toxic effects of acute oral exposure of p-Phenylenediamine on the kidney of adult male albino rats and measurement of the level of PPD and its main metabolites (MAPPD and DAPPD) in the blood and the kidney by HPLC-DAD.

\section{1- HPLC results:}

The presented extraction procedure offers a rapid way to isolate PPD and its metabolites (MAPPD\&DAPPD) from the biological samples whereas extraction with dichloromethane in the presence of ammonia results in a clean HPLC chromatograms and excellent peak shape.

The limit of detection of PPD, MAPPD and DAPPD was (500, 250 and 250ng/ml respectively). Graph (4) show HPLC chromatogram for the analysis of plasma sample collected from one of LD50 treated rat where the peaks for PPD, MAPPD, DAPPD and IS were investigated by photo-diode array detector and found to be pure (peak purity more than 99\%). Quantification of PPD and its metabolites (MAPPD and DAPPD) in blood and kidney samples were checked by the present method. PPD can be detected in the plasma only in group IV which died rapidly after dosing before its metabolism and distribution into the tissues while in the kidney can be detected in all groups due to the aromatic structure of PPD, making it easily reabsorbed and concentrated in tubules this in contrast of the metabolites which can be detected in both plasma and kidney in all groups and their levels increased with increased doses. 


\section{2- Biochemical results:}

Urea is quantitatively the most important solute excreted by the kidney and was the first organic solute detected in the blood of patients with kidney failure. In the current study, it was found that there was significant increase in the mean values of serum urea in all PPD treated rat groups as compared with control group.

In spite of the significant increase in the mean value of serum creatinine (SCr) in group II PPD treated rats as compared with control group (group I), and significant difference in the mean values of serum urea and serum creatinine among all PPD treated groups ( $p$ $<0.001$ and 0.01 respectively), there was no significant difference in the mean values of serum creatinine in group III and IV PPD treated rats as compared with control group. This can be explained that the serum urea concentration may increase out of proportion with changes in $\mathrm{SCr}$ as $\mathrm{SCr}$ values may not show significant increases until approximately $50 \%$ of kidney function is lost. Rather, $\mathrm{SCr}$ requires time to accumulate prior to being detected as abnormal (Finn and Porter, 2008). This is the case in the current study where $\mathrm{SCr}$ increased in group II which were slaughtered after 24hours i.e. SCr had sufficient time to accumulate while it was not significantly increased in groups III and IV which were slaughtered after 4-8hrs.

These results are in agreement with (Saad et al., 2000) in their study of the systemic toxicity of pphenylenediamine (PPD) on Brown Hisex chicks and Albino Wister rats, at different concentrations through different routes of administration where death occurred at doses $105,140, \mathrm{mg} / \mathrm{kg}$ body weight (B.wt.) in chicks and at doses $35 \mathrm{mg} / \mathrm{kg}$ B.wt. in rats within 4 and $3 \mathrm{hrs}$, respectively and the concentrations of urea, uric acid, and creatinine elevated with maximum toxic effects of single sublethal dose of PPD was at $24 \mathrm{~h}$ in rats and 72 hrs in chicks.

The current results are in correspondence with Kallel et al. (2005) who stated that the kidneys are particularly vulnerable to the toxic effect of PPD and that acute renal failure development testifies to the severity of intoxication and predicts poor prognosis. Also, the present results go with those of Singla et al. (2005) and Filali et al. (2006) who described two phases of serious toxic effects following acute PPD poisoning; first phase usually appears within 4-6 hours and is manifested by severe edema of the face and neck while the second one develops in 12 hours post ingestion in which rhabdomyolysis and acute renal failure supervene.

According to Ram et al. (2007) who stated that the pathogenesis of acute tubular necrosis may be independent of rhabdomyolysis and it appears to be due to the aromatic structure of PPD, making it easily reabsorbed and concentrated in tubules.

\section{3- Histopathological results:}

The present histopathological findings are consistent with (Sampath and Yesudas, 2009) study who reported that renal structure shows acute tubular necrosis in PPD toxicity. Also (Chugh et al. 1982) described the histological change of acute tubular necrosis in PPD poisoning as vacuolar degeneration, nuclear pyknosis and cytoplasmic vacuolations brush border damage.

The most pronounced histological changes that observed in glomerular cells in previous experiment were similar to those described in tubular cells in present study such as vacuolization of tubular cells with necrotic changes of many mesangial cells and podocytes (Hummdi, 2012). Tubular obstruction may be caused by release of cytoplasmic fragments mixed with intratubular proteins. This can lead to increased intratubular pressure, which again may result in sufficient back pressure to alter the transglomerular hydrostatic pressure.

These histological changes typical of acute tubular necrosis have been also reported in a prospective study performed in Khartoum Kidney Dialysis Centre and Sheffield Kidney Institute in which 19 renal biopsies out of a series of 23 patients with severe $(39 \%)$, moderate $(35 \%)$ and mild intoxication with PPD (26\%) were studied under light microscopy. Glomerular injury observed in $94 \%$ of the biopsies in the form of hypercellularity, membranous proliferation, glomerular swelling, and capsular drop tubular lesions were found in $78.9 \%$ of the studied samples. (Hamdouk et al., 2008).

\section{Conclusion}

It has been found that PPD affects the kidney both functionally and pathologically which increased with the increase of the dose and the duration of exposure.

\section{Recommendations}

- It is advised to restrict and control the use of PPD.

- Rapid and accurate management for toxic cases by increasing the number of specialized toxicology centers.

- Increase physicians' awareness by clinical manifestations of PPD toxicity and lines of management and importance of rapid interference and referral to specialized center.

\section{References}

Averbukh Z., Modai D., Leonov Y. et al., (1989): Rhabdomyolysis and acute renal failure induced by paraphenylenediamine. Hum Toxicol; 8: 345-348.

Bourquia, A., Jabrane A.J., Ramadani B. et al., (1988): Systemic toxicity of paraphenylenediamine. Presse Medical, 17: 798. 
Charra B, Menebhil L, Bensalama A, et al., (2000): Systemic toxicity of paraphenylene diamine. Works of the Sixth Congress of the Arab Society of Nephrology and Renal Transplantation.

Chugh, K.S., G.H. Malik and P.C. Singhal, (1982): Acute renal failure following paraphenylene diamine. [Hair dye] poisoning: report of two cases. J. Med., 13: 131-137.

Filali A., Semlali I., Ottaviano V. et al., (2006): A retrospective study of acute systemic poisoning of paraphenylene diamine (Ocidental Takawt) in Morocco. African Journal of Traditional, Complimentary and Alternative Medicines, 3: 142-149.

Finn W. F. and Porter G. A. (2008): Urinary biomarkers and nephrotoxicity. In Clinical Nephrotoxins. Renal Injury from Drugs and Chemicals. $3^{\text {rd }}$ ed. Ch. 6 . Springer Science Business Media, LLC: 97-98.

Hamdouk M. I., Mohamed B. Abdelraheem, Ahbab A. Taha et al., (2008): Paraphenylene diamine hair dye poisoning. In Clinical Nephrotoxins. Renal Injury from Drugs and Chemicals. $3^{\text {rd }}$ ed. Ch. 40 . Springer Science Business Media, LLC: $871-881$

Hashim M. Sir, Hamza Y.O., Yahia B. et al., (1992): Poisoning from henna dye and paraphenylenediamine mixtures in children in Khartoum. Annals of Tropical Paediatrics;12: 3-6.

Hummdi L. A., (2012): Histopathological Alterations in Renal Tubules of Female Rats Topically Treated with Paraphenylen diamine. World Applied Sciences Journal 16: 376-388.

Kallel H., Chelly H., Dammak H.et al., (2005): Clinical manifestations of systemic paraphenylene diamine intoxication. J NEPHROL., 18: 308311.

Kazuhiro K. and Takaaki K. (2005): Hair dyes. In Drugs and Poisons in Humans A Handbook of Practical Analysis. Editors, Osamu Suzuki and Kanako Watanabe. Ch. 5. Springer-Verlag Berlin Heidelberg New York: 415-425.

Kawakubo. X., Merk. H. F., Masaoudi T. et al., (2000): Acetylation of paraphenylenediamine in human skin and keratinocytes. J. Pharm. Exp. Therapeut., 292: 150 - 155.

Krishnaswamy S. and Sooraj Y. (2009): Hair dye poisoning and the developing world. J Emerg Trauma Shock; 2: 129-131

Mathur K. K., Gupta B. N., Narag S., et al. (1990): Biochemical and histopathological changes following dermal exposure to paraphenylenediamine in guinea pigs. J Appl Toxicol;10: 383-386.

Meyer U. A. and Zanger U. M. (1997): Molecular mechanisms of genetic polymorphisms of drug metabolism. Annu Rev Pharmacol Toxicol 37: 269-296.

Mohamed A., Mohamed H. and Eduard E. Z. (2010): Paraphenylene Diamine (Hair Dye) Poisoning in Children. Arab Journal of Nephrology and Transplantation; 3: 39-43.

Mohamed KM, Hilal MA, Nady S. Aly (2014): Fatal Intoxications with Para-Phenylenediamine in Upper Egypt. Int J Forensic Sci Pathol.; 2: 1923.

Othman M. M. (2001): Acute Poisoning with Hair dye Containing Paraphenylene Diamine - The Gazira Experience. Journal of the Arab Board of Specialization: 3 .

Ram R., Swarnalatha G., Prasad N., and Dakshinamurty K. V. (2007) Paraphenylenediamine ingestion: an uncommon cause of acute renal failure. Journal of Postgraduate Medicine, 53: 181182.

Saad H. A., Mousa H. M. and Ali B. H. (2000): Some toxicological observations on phenylenediamine (hair dye) in rats and chickens. Pak. J. Biol. Sci.; 3: 953-956.

Schnuch A., Geier J., Uter W et al., (1997): contact dermatitis, 37: 200 .

Sampath K. K. and Yesudas S. (2009): Hair dye poisoning and the developing world. J Emerg Trauma Shock; 2: 129-131.

Singla S., Miglani S., Gupta P. et al., (2005): Paraphenylenediamine (PPD) poisoning. Journal of Indian Academy of Clinical Medicine, 6: 236-238. 


\section{الملخص العربي}

\section{التأثيرات السمية الحادة لمادة البارافينيلين ديامين علي الكلي بعد جرعة واحدة بالفم: دراسة تجريبية}

\section{عبد الوهاب عبد الكريم داوود' و مها عبد الحميد هلال و سهير علي محمد و رضا محمد السيد و خالد مسعود محمدّ و هدي}

\section{محمد السيد؛}

المقدمة: مركب البارافينيلين ديامين (PPD) هو مركب صناعي يستخدم على نطاق واسع في صباغة الشعر . تناول البارافينيلين ديامين

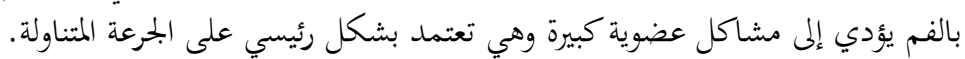

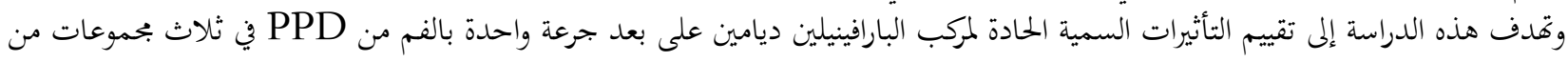

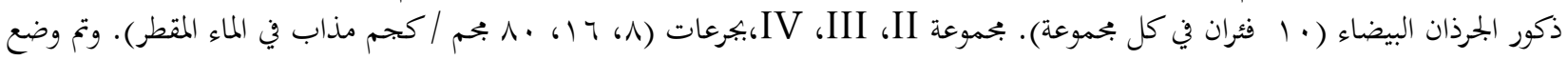

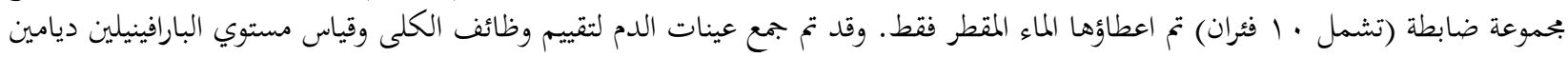

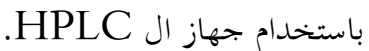

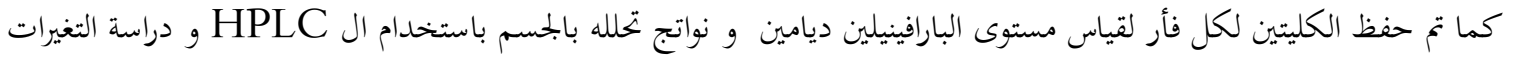

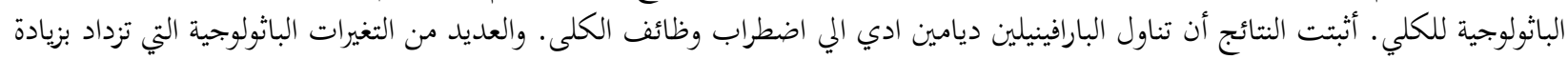

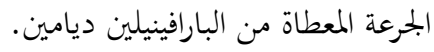

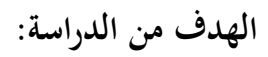

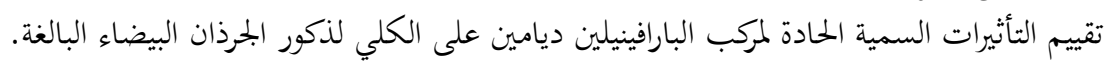

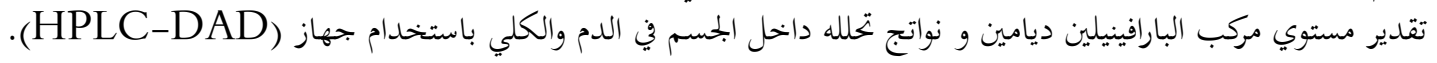

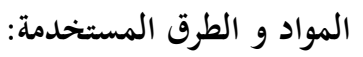

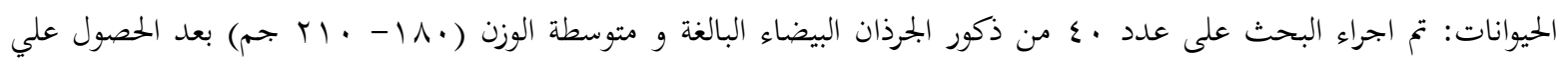

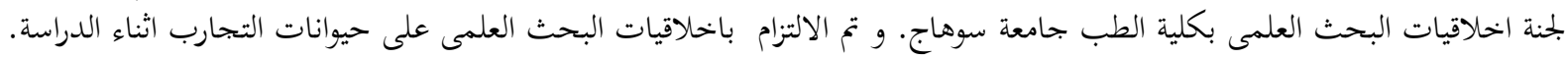
المواد: البارافينيلين ديامين مذاب في الماء المقلية المقرة

\section{الأجهزة:}

وظائف الكلي باستخدام جهاز القياس الطيفي (Beckman Coulter AU480 Clinical Chemistry System)

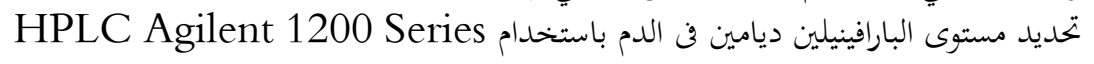

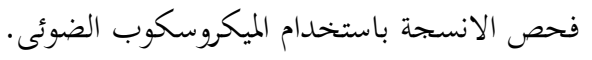

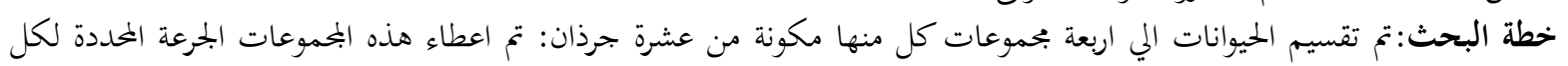

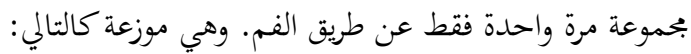

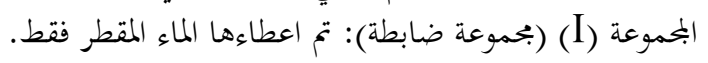

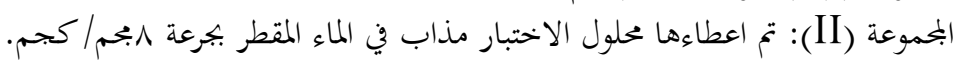

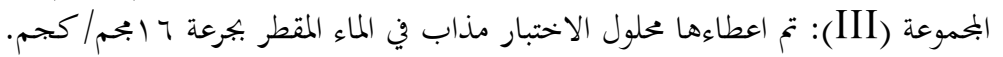

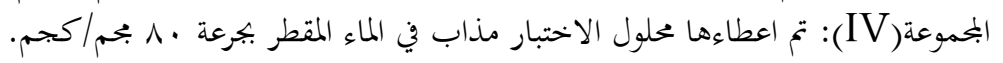

وفي نهاية الدراسة: 1 - تم جمع عينات الدم لعمل التحاليل الاتية • • • •حليل وظائف الكلي (نسبة اليوريا والكرياتنين) قياس نسبة CPK

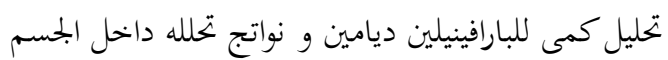

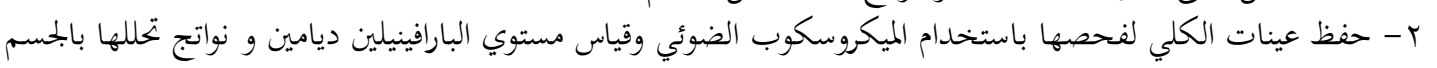

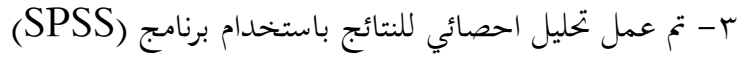

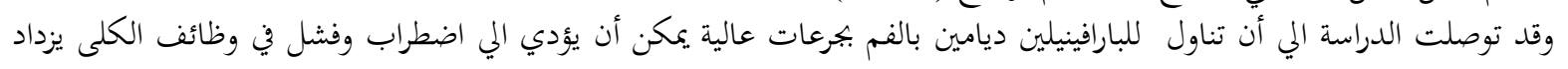

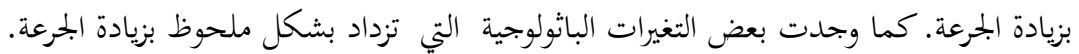

